Article

\title{
The Tale of an Intake Vortex and Its Mitigation Countermeasure: A Case Study from Akkats Hydropower Station
}

\author{
James Yang 1,2,*(D), Patrik Andreasson ${ }^{1,3}$, Carl-Maikel Högström ${ }^{1}$ and Penghua Teng 2 (D) \\ 1 Vattenfall AB Research and Development, Älvkarleby Laboratory, SE-81426 Älvkarleby, Sweden; \\ patrik.andreasson@vattenfall.com (P.A.); carl-maikel.hogstrom@vattenfall.com (C.-M.H.) \\ 2 Division of Resources, Energy and Infrastructure, Royal Institute of Technology, SE-10044 Stockholm, \\ Sweden; teng.penghua@byv.kth.se \\ 3 Division of Fluid and Experimental Mechanics, Luleå University of Technology, SE-97187 Luleå, Sweden \\ * Correspondence: james.yang@vattenfall.com; Tel.: +46-26-83564
}

Received: 8 May 2018; Accepted: 28 June 2018; Published: 2 July 2018

\begin{abstract}
The upgrade of Akkats power station in Sweden included a new, separate waterway for the addition of a $75 \mathrm{MW}$ generating unit. The vertical intake of its headrace was formed by means of lake tapping. A physical model was used to help understand the blasting process involving fragmented rock, water, air, and gas. Upon commissioning of the unit, swirling flows occurred unexpectedly at the intake, which gave rise to negative consequences including limitations in power output. Echo-sounding showed that the blasted piercing resulted in an irregular intake. A hydraulic model, as part of the design process, was built to examine potential countermeasures for vortex suppression. The final solution was a segmented barrier between the intake and the dam. It effectively suppressed the intake flow circulations; only minor intermittent vortices were left. The fabricated steel segments were anchored into the bedrock, stretching to $1.0 \mathrm{~m}$ below the lowest legal reservoir level. The local intake headloss was also reduced. The implemented solution was tested under full turbine loading and the result was satisfactory. Even during winter seasons with ice cover above the wall, the power station ran normally. The case study is expected to provide guidance for solving similar problems with vortex formation.
\end{abstract}

Keywords: Akkats; intake; lake tapping; swirling flow; vortex suppression; model tests

\section{Background}

Akkats hydropower station is located on the Lule River in North Sweden. The facility, constructed between 1969-1973, was equipped with one $150 \mathrm{MW}$ unit at a $45 \mathrm{~m}$ gross head and a $385 \mathrm{~m}^{3} / \mathrm{s}$ turbine flow rate. Since its commissioning in 1973, the plant suffered from a number of incidents that were complicated to repair and led to long shutdown periods. A major breakdown that occurred during 2002 limited the power production to $80 \%$ of its full effect. Decisions were therefore made to refurbish the power plant by replacing its existing unit with two smaller but more efficient ones, each operating at a turbine discharge of $200 \mathrm{~m}^{3} / \mathrm{s}$ and having an installed effect of $75 \mathrm{MW}$ [1]. One unit (unit B) was placed in the location of the existing unit; the other one (unit A) was installed to its left, for which a new, separate waterway, including a headrace with an intake in the reservoir and a tailrace tunnel, was excavated in rock (Figure 1). After the upgrade, the power production amounted to $590 \mathrm{GWh}$ annually, 26 GWh of which was attributable to the increase in the turbine efficiency. 


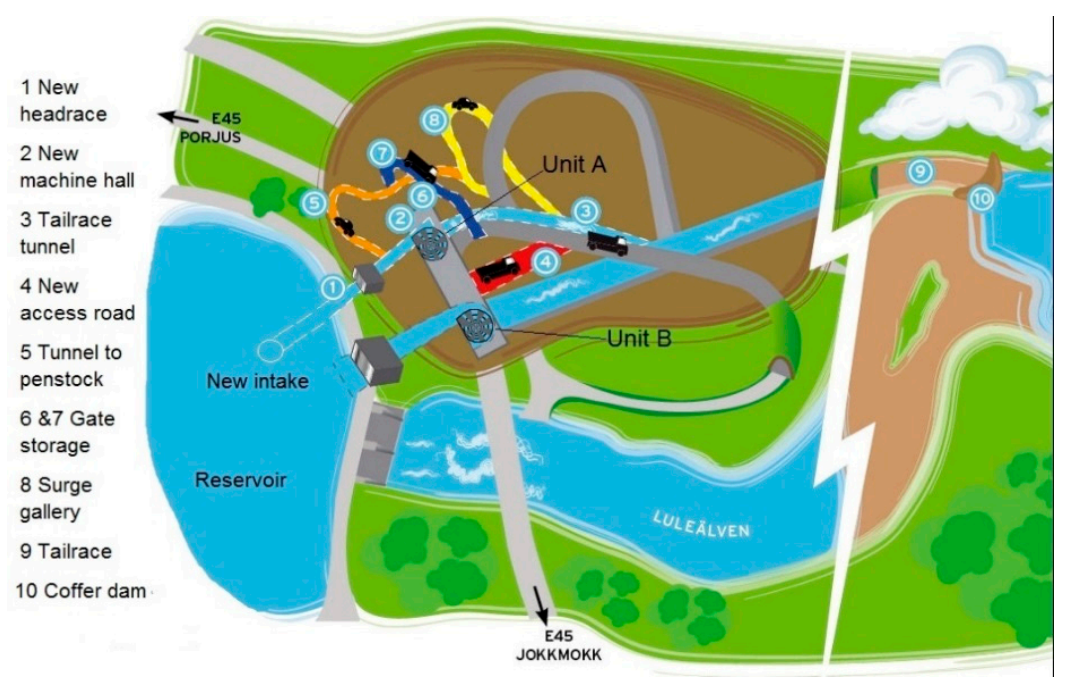

Figure 1. Layout of Akkats hydropower station after upgrade [2].

During the construction of the waterway for unit A, the reservoir water level was maintained at its normal elevation. The headrace tunnel was excavated from downstream to the would-be location of the intake. The plug of natural rock between the headrace and the reservoir was blasted by so-called lake tapping to form the intake. Before the construction, model tests were performed to help understand the impact of the blasting on the waterway. Upon commissioning, swirling flows occurred at the intake, which was due to insufficient water depth. A hydraulic model was built to evaluate potential counter-measures for vortex suppression. In addition to the reason for the plant upgrade, the paper also includes the following parts: (1) lake tapping and its model tests; (2) prototype turbine commissioning with vortex occurrence; (3) model tests with vortex mitigation measures; and (4) implementation in the prototype.

\section{Lake Tapping}

Lake tapping is used in projects where a new waterway is to be added without lowering the lake or reservoir water level. It involves excavation of the tunnel in rock from below a lake or reservoir, finally leaving a rock plug of limited thickness in the lake bottom. The plug is then blasted from below and the bottom is pierced to form the intake. Many lake taps have been carried out in Norway and other countries [3-6].

The underwater tunnel piercing is divided in two main categories: an open system and a closed system. The former refers, during the blast, to direct communication between the tunnel and the gate shaft open to the atmosphere; the system is sealed downstream of the shaft. The latter refers to sealing of the system upstream of the shaft. A concrete wall or a steel gate is usually used to seal the system. The theoretical and practical aspects of the two systems are discussed and summarized in References [7-9]. Each system has its advantages and disadvantages and should be selected according to site-specific conditions. Despite a well-proven solution, each project is unique and the impact of blasting needs to be examined in terms of tunnel length, surge oscillations, dynamic forces, risks, costs etc.

The range of Akkats reservoir water-level variations was between $+258.0 \mathrm{~m}$ (SG) and $+259.5 \mathrm{~m}$ (DG), corresponding to which the water depth at the intake was 8.0-9.5 m. SG and DG refer to the lowest and highest water levels of the dam stipulated by the law. The headrace tunnel with the rock plug is shown in Figure 2. The tunnel was given an upward slope in the flow direction to prevent transport of blasted rock fractions downstream. Downstream of the gate shaft, the penstock bent $90^{\circ}$ downwards, leading to the turbine. The tunnel cross-sectional area was $80 \mathrm{~m}^{2}$. The plug had a cross-sectional area of $100 \mathrm{~m}^{2}$ and a thickness of $6 \mathrm{~m}$, resulting in a rock volume of $600 \mathrm{~m}^{3}$. The tunnel 
section between the plug and the gate shaft was $60 \mathrm{~m}$ long. It was decided that the so-called open piercing method should be used, with construction of a concrete wall to seal the passage to the penstock. The piercing generated surges oscillated between the reservoir and the shaft. Pre-filled water in the tunnel and air pocket trapped below the plug dampened the impacts. Below the intake, a debris trap was proposed to accommodate the blasted rock masses. The sealing wall was removed before the unit was put in operation.

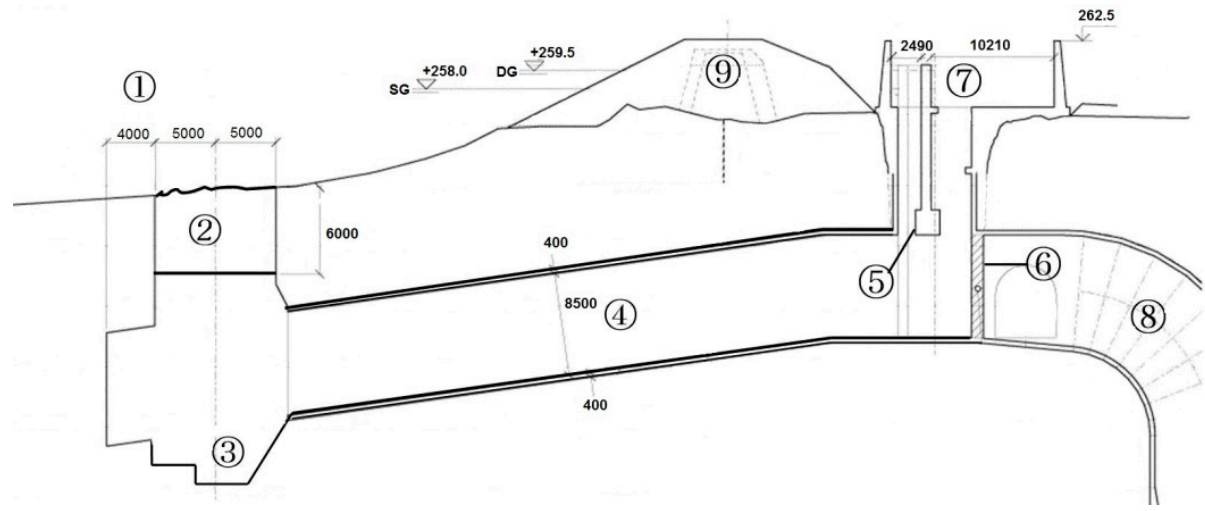

Figure 2. Headrace layout with: (1) reservoir; (2)rock plug; (3) stone pit location; (4) tunnel; (5) partition wall; (6) concrete sealing wall; (7) gate shaft; (8) penstock; and (9) embankment dam.

Underwater tunnel piercing was a complex process. It involved four phases of solid rock, water, air, and gas produced by the explosive. There were no modelling rules to follow for laboratory model studies; the phenomenon could only be examined in an approximative manner. The purposes of model studies were to work out a suitable shape of the stone pit, to determine a proper level of water pre-filling in the headrace and the maximum upsurge height in the shaft, to identify the risk of blasted rock transport downstream into the tunnel and the dynamic load acting upon the concrete sealing wall $[10,11]$.

The test rig is shown in Figure 3. The model was in the scale 1:30 and included the headrace from the intake to the shaft. A tank with a size of $200 \times 200 \mathrm{~cm}$ formed the upper reservoir. A sharp-edged weir was mounted on one side of the tank to maintain desired constant water level during the tests. On one side, the headrace and the shaft were covered with thick Plexiglas plates to facilitate observations.

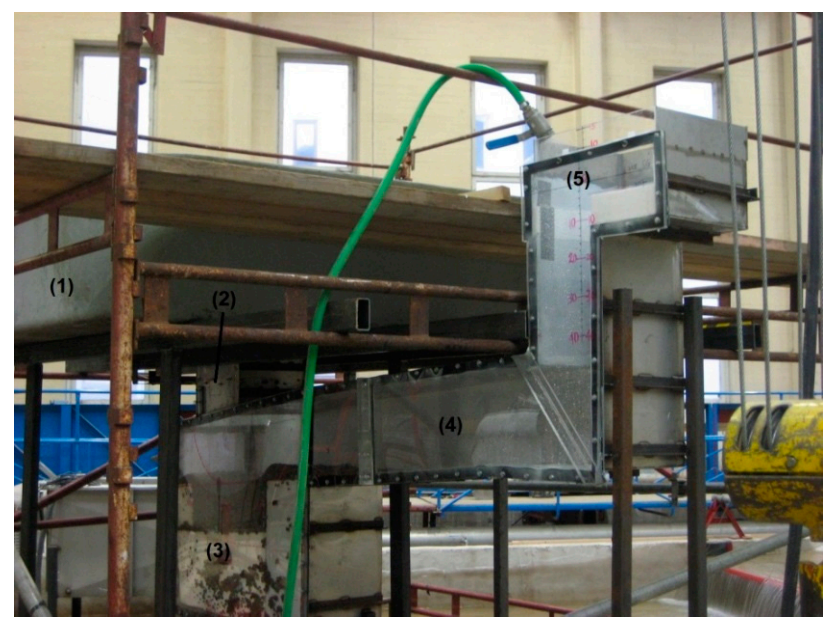

Figure 3. Experimental setup. (1) Reservoir; (2) intake with rock plug; (3) stone pit; (4) headrace tunnel; and (5) gate shaft open to the atmosphere. 
The intake was placed in the middle of the tank. The plug's cross-section was $33 \mathrm{~cm}$ by $33 \mathrm{~cm}$ (Figure 4). Depending on the amount of explosive used and rock quality, the rock volume after blasting increased, as a rule of thumb, by 40-60\%. Previous tunnel blasting indicated that blasted rock could have rock sizes up to $20-30 \mathrm{~cm}$. A mixture of crushed stone and sand of $0.2-1.2 \mathrm{~cm}$ was used. On the basis of the mixture porosity, the blasted rock volume increased by about $50 \%$ in the model, thus giving a plug height of $40 \mathrm{~cm}$. A horizontal gate, mounted under the tank and operated pneumatically, was "instantaneously" opened to release the rock mass and simulate the blasting.

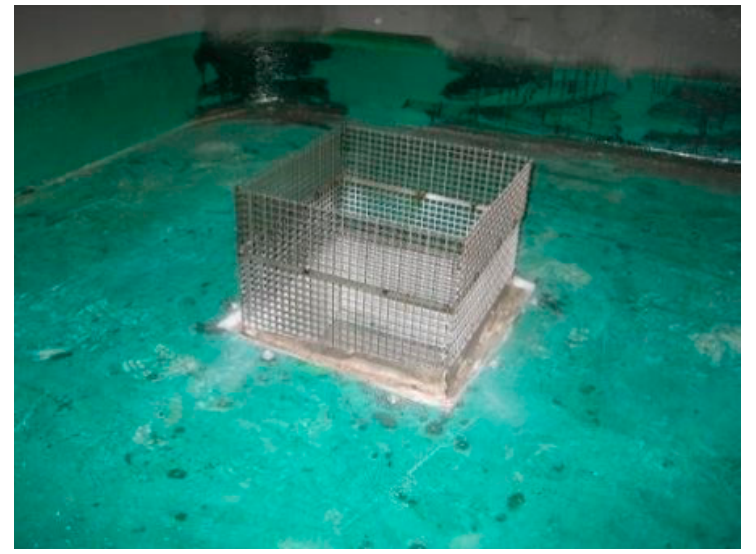

(a)

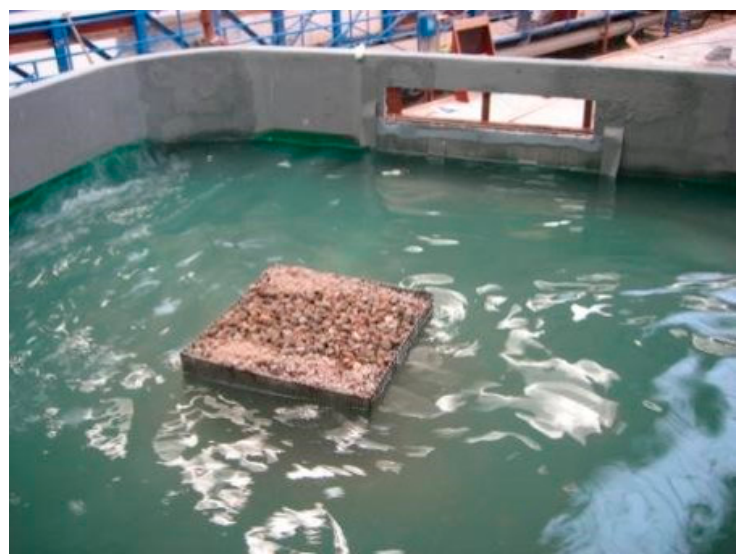

(b)

Figure 4. Intake arrangement to simulate the blasting. (a) rectangular net frame to model the plug; (b) intake filled with a mixture of crushed stone and sand.

In the headrace bottom below the plug, a stone pit was excavated to accommodate the blasted rock masses. The desirable deposit profile should be smooth and did not cause extra headloss for power generation (Figure 5). For this purpose, a few stone pit layouts were examined. The pit should also be large enough to prevent stone transport further downstream in the headrace.

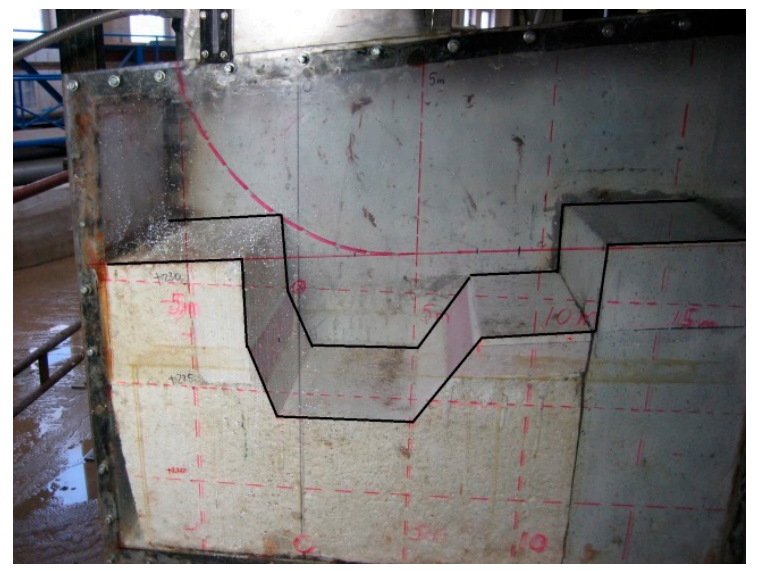

(a)

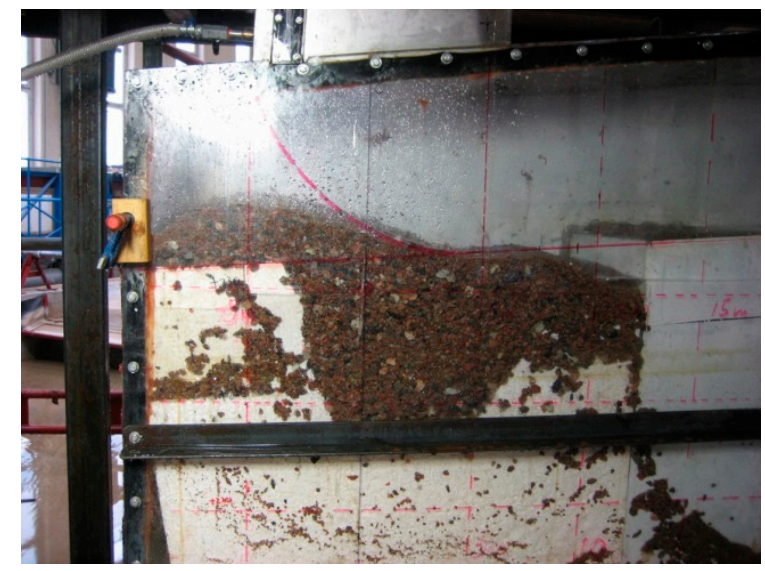

(b)

Figure 5. Stone pit configuration and profile of blasted rock mass in the tunnel. (a) one stone pit shape tested; (b) resulting profile from the blasting.

The tunnel and the shaft were pre-filled with water. The pre-filling was necessary to limit the upsurge in the shaft and the load acting on the sealing wall. A few pre-filling water levels were examined to look at the differences. Through repeated tests, it was found that it is only if the shaft water level was equal to the reservoir water level that the resulting upsurge level was the lowest. In relation 
to the reservoir water stage, the height of the gate shaft was limited. No matter what countermeasure was adopted to suppress the upsurge, the shaft was always overtopped, which was not allowed. Manometers were installed in the sealing wall to monitor the dynamic pressure. The measurements showed that, if the plug was removed by only one blast, the force on the wall would be too large. An excessively thick wall would be difficult to demolish before the commissioning.

Lake tapping involved a certain amount of gas in the blast. Each kilogram of explosive produced approximately $0.8 \mathrm{Nm}^{3}$ of gas. The interaction between the rock fragments, water, gas, and air was difficult to simulate in a scalable way in the laboratory. Taking into consideration the nature of the issue, a decision was made that the rock plug be divided and blasted in a sequence. In such a way, both the upsurge amplitude and the dynamic load on the sealing wall became limited.

\section{Commissioning and Occurrence of Vortex}

As suggested by the model tests, the lake tapping was successfully executed, with the rock plug removed with sequential detonations. Inspections were then made with the help of a diver. Upon its completion, commissioning tests of unit A were performed, during which the reservoir water level was at $+258.3 \mathrm{~m}$ and unit B was in its normal operation. The tests were only observed visually. The test time was in the beginning of May. The ice cover in the reservoir had already disappeared. However, there existed ice floes, though limited in number, in the water.

In the first test, when unit A was phased in, its load was kept at $42 \mathrm{MW}$ for $50 \mathrm{~min}$. One could see a first sign of vortex formation at the intake location, circulating anti-clockwise. The diameter of the air core was approximately 1-1.5 m. The turbine load increased then to $77 \mathrm{MW}$ and lasted for $60 \mathrm{~min}$. The vortex strength increased accordingly and the air-core diameter was around 3-4 m. Figure 6 shows a picture of the vortex, taken from the intake to unit B. Two wooden beams, 0.7 and $1.8 \mathrm{~m}$ in length, were dropped into the water. They approached the vortex, got trapped in it, and followed the swirling flow in the air core. After the load rejection, the beams floated up and came to the water surface.

In the second test, the effect of unit A was kept at $80 \mathrm{MW}$ that lasted for $50 \mathrm{~min}$. An anti-clockwise vortex occurred of the same size as at $77 \mathrm{MW}$ in the first test. The vortex was relatively stable in position. With the main vortex, one could see also the recurrence of two smaller secondary vortices. To facilitate observations, two wooden beams (1.0 and $2.0 \mathrm{~m}$ long) and five oranges were thrown into the circulating water. With time, all the objects were "sucked" into the vortex and rotated with the flow. Even some ice floes got trapped in the swirling water. The time needed for an orange to fulfill one revolution was $35 \mathrm{~s}$. After the load-off, the two beams and four of the five oranges floated to water surface. No sign of air pockets or trapped air was observed coming out of the intake.

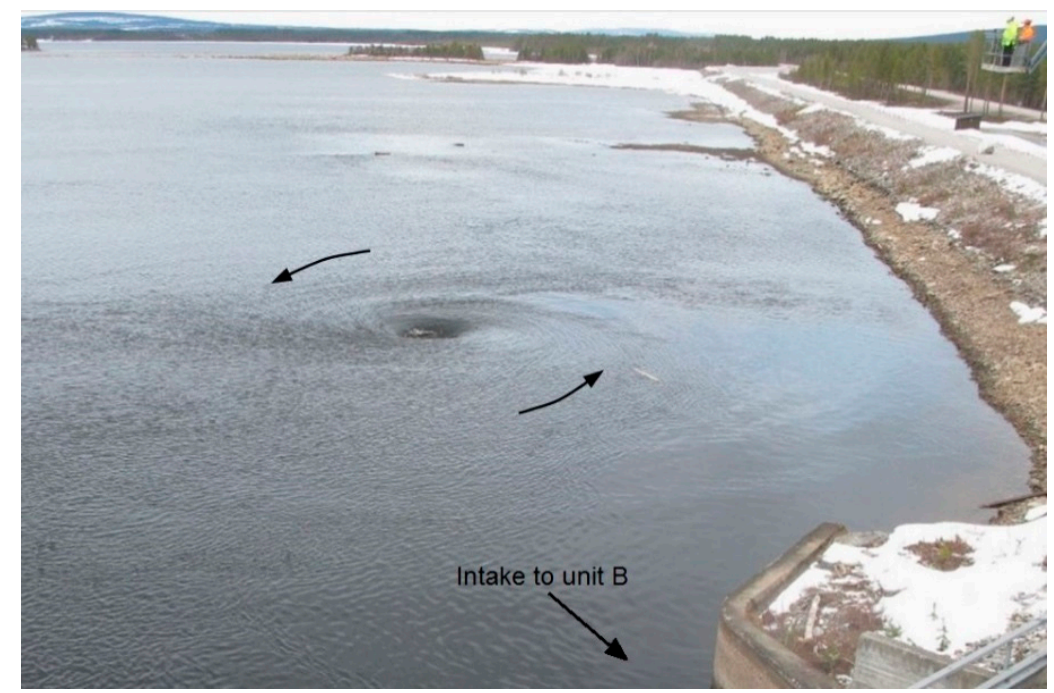

Figure 6. Occurrence of intake vortex upon commissioning of unit A. 
The blasted intake to unit A was located to the left of the main river course. In the middle of the river, the larger mass flux of the approach flow gave rise to the anti-clockwise swirling flow at the intake, which was expected. The occurrence of the vortex was objectionable in many ways. The flow velocity at the dam toe became higher and the concern for erosion arose. It increased the local headloss at the intake and limited the power production. There was also the risk that it would pull floating debris including ice floes into the water and transport stones to the turbine. The vortex was not stable; it resulted in rotating flows in the headrace. Turbine vibrations, though minor, were also observed.

To avoid the vortex formation and related problems, unit A operated only at partial loads. At the same time, in situ bathymetric survey was made with a multi-beam echo-sounder to map the resulting intake shape from the lake tapping. Figure 7 shows the intake configuration, which was irregular in elevation and approximately circular in plan. The vertical intake was originally designed to have a nominal cross-sectional area of $100 \mathrm{~m}^{2}$. The resulting minimal area was only $A=87.6 \mathrm{~m}^{2}$ (equivalent diameter $D=10.56 \mathrm{~m}$ ). Given the $200 \mathrm{~m}^{3} / \mathrm{s}$ turbine flow rate, the intake velocity was $V=2.3 \mathrm{~m} / \mathrm{s}$. The water depth above the intake ranged between $H=8.0-9.5 \mathrm{~m}$.

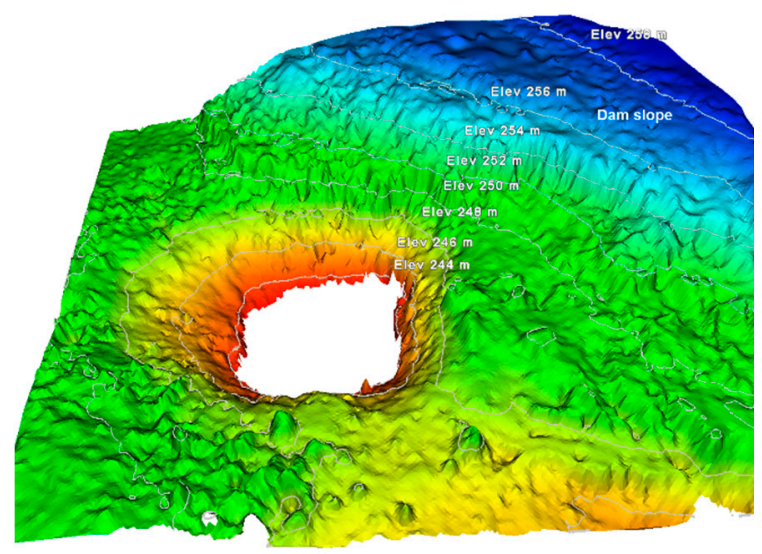

(a)

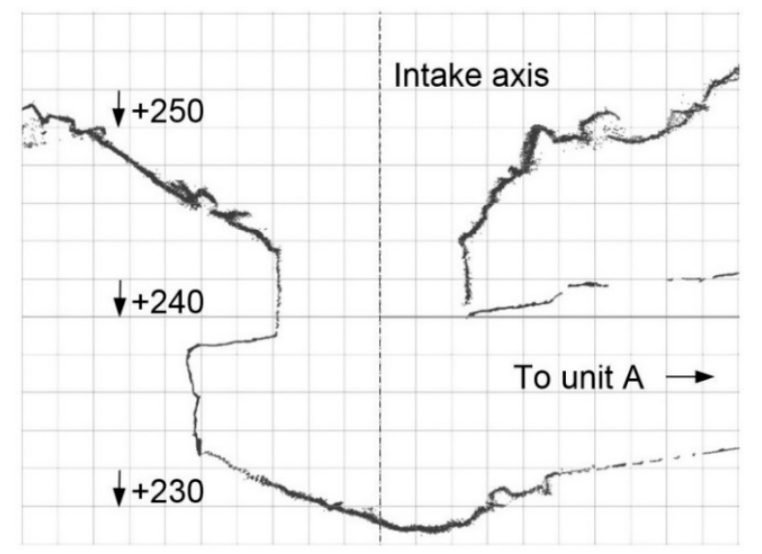

(b)

Figure 7. Intake shape resulting from the lake tapping. (a) result from echo-sounding; (b) longitudinal profile along the tunnel axis.

The vortex formation is a flow phenomenon dominated by gravity, flow circulation, and viscosity. To avoid this, the water depth above the intake must be sufficiently large. The critical depth of submergence $\left(H_{c}\right)$ refers to the water depth of incipient air entrainment, with the tip of the air core at the entrance cross-section [12]. The dominant parameters of the problem include $D, V$, and $H$. The intake Froude number is usually defined as $\mathrm{F}=V /(g D)^{\frac{1}{2}}$, where $g$ is the gravitational acceleration. A commonly used criterion for determination of $H_{c}$ at vertical cylindrical intakes reads $H_{c} / D=4.5 \mathrm{~F}^{0.5}[13,14]$. For the Akkats case, $V=2.3 \mathrm{~m} / \mathrm{s}$ and $D=10.56 \mathrm{~m}$, this led to $\mathrm{F}=0.23$ and $H_{c} \cong 22.8 \mathrm{~m}$, which was compared to $H=8.0-9.5 \mathrm{~m}$. A check against other similar criteria showed that the intake was not located sufficiently deep and its water depth did not satisfy the submergence requirement [14-16]. The vortex formation was thus inevitable.

\section{Model Studies of Vortex Suppression}

To achieve acceptable operating conditions at the blasted intake, the need to suppress the swirling flows was obvious. A physical hydraulic model was constructed for this purpose (Figure 8). The model was based on the Froude law of gravity similarity. The scale chosen was $1: \lambda=1: 30$, so that the intake size was reasonably large.

To correctly reproduce the approaching flow to the generating units and the spillway, the reservoir area included was sufficiently large, $300 \mathrm{~m}$ long and covering the whole river width of about $300 \mathrm{~m}$. The gated spillway section and the intake to unit B were also built in. The model was $12 \mathrm{~m} \mathrm{long}, 11 \mathrm{~m}$ 
wide, and about $1.5 \mathrm{~m}$ above the floor. The highly irregular shape of the intake made it difficult to construct in a traditional way. To model the intake with accuracy, it was reproduced by means of 3D printing (Figure 9).

The maximum inflow to the model amounted to $195 \mathrm{~L} / \mathrm{s}$ with one pump and $390 \mathrm{~L} / \mathrm{s}$ with two pumps. Both the inflow and turbine flow rates were measured with magnetic flow meters. Point gauges read water levels in the reservoir; manometers measured water pressures in the headrace of unit A. The data of the reservoir levels and headrace pressures gave indications of head-loss changes before and after any vortex mitigation countermeasures. A 3D Doppler velocimeter was used to measure flow velocities at locations of interest when necessary.

The spillway had two radial gates, each $15-\mathrm{m}$ wide. Their total discharge capacity amounted to $1900 \mathrm{~m}^{3} / \mathrm{s}$. After the upgrade, the turbine flow rate of each unit was $200 \mathrm{~m}^{3} / \mathrm{s}$. The flow rates and velocities in the prototype $(Q, V)$ and the model $\left(Q_{m}, V_{m}\right)$ are converted according to the relationships $Q / Q_{m}=\lambda^{2.5}$ and $V / V_{m}=\lambda^{0.5}$. Four major flow conditions (Case a, b, c, and d) were reproduced in the model to observe the intake behaviors. In all cases, unit A operated at full load, $200 \mathrm{~m}^{3} / \mathrm{s}$, with the reservoir water level at $+258.0 \mathrm{~m}$ (SG). The flow parameters are summarized in Table 1 , where $Q_{m, A}$ and $V_{m, A}$ refer to the flow rate and intake flow velocity of unit A.

- Case a-running of unit A alone

- Case b-running of both units

- Case c-running of unit A combined with a rate of $400 \mathrm{~m}^{3} / \mathrm{s}$ in the left spillway opening

- Case d-running of both units combined with $200 \mathrm{~m}^{3} / \mathrm{s}$ in the right spillway opening

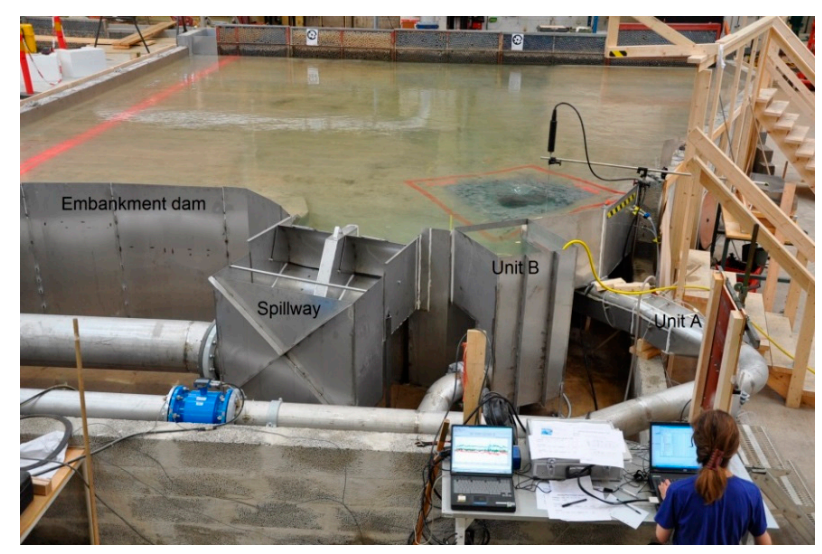

Figure 8. Hydraulic model tests of intake vortex suppression, model scale $\lambda=30$.

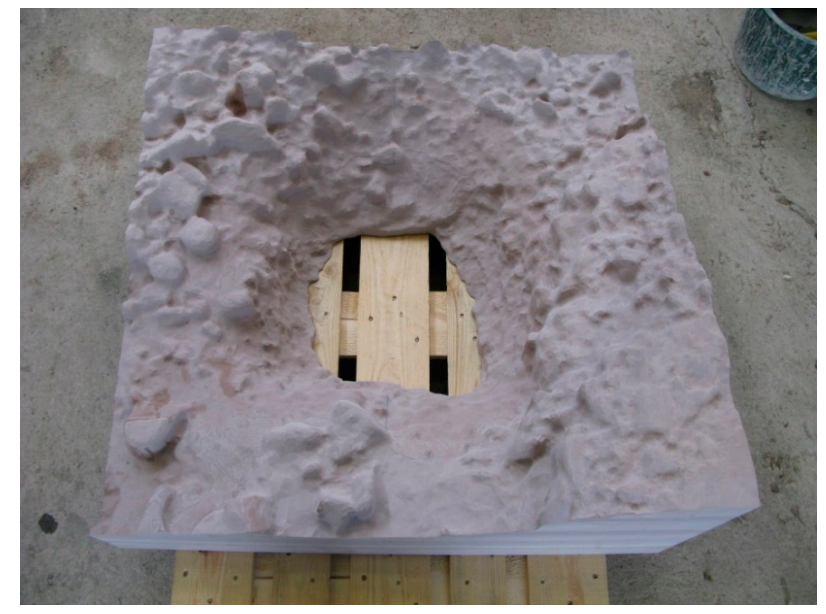

Figure 9. The blasted intake configuration reproduced from 3D printing. 
Table 1. Four major flow cases examined at SG, with unit A at full load.

\begin{tabular}{ccccc}
\hline Flow Case & a & b & c & d \\
\hline$Q\left(\mathrm{~m}^{3} / \mathrm{s}\right)$ & 200 & 400 & 600 & 600 \\
$Q_{m}(\mathrm{~L} / \mathrm{s})$ & 40.6 & 81.2 & 121.8 & 121.8 \\
$Q_{m, A}(\mathrm{~L} / \mathrm{s})$ & \multicolumn{5}{c}{40.6} \\
$V_{m, A}(\mathrm{~m} / \mathrm{s})$ & \multicolumn{5}{c}{0.42} \\
\hline
\end{tabular}

Figure 10 shows vortex formations of the four typical cases, with the reservoir water set at SG. With only unit A in operation (Case a), an anti-clockwise vortex occurred at the intake, with an obvious air core of 7-9 cm in diameter. The water surface nearby was relatively smooth. With both units in operation (Case b), the air core diameter increased somewhat to 10-13 cm; the swirling flow affected a larger water-surface area. The combination of unit A with the left spillway (Case c) seemed to have an accelerating effect on the swirling flow; the water surface became more rugged and wavy. Case $\mathrm{d}$ was similar to Case c. An additional spillway discharge of more than $200 \mathrm{~m}^{3} / \mathrm{s}$ in either Case c or $\mathrm{d}$ led to a higher flow flux in the middle of the reservoir. This would influence and smear the vortex. As a result, the vortex disappeared and recurred at intervals. In either case of the tests, no air ingression was observed into the headrace.
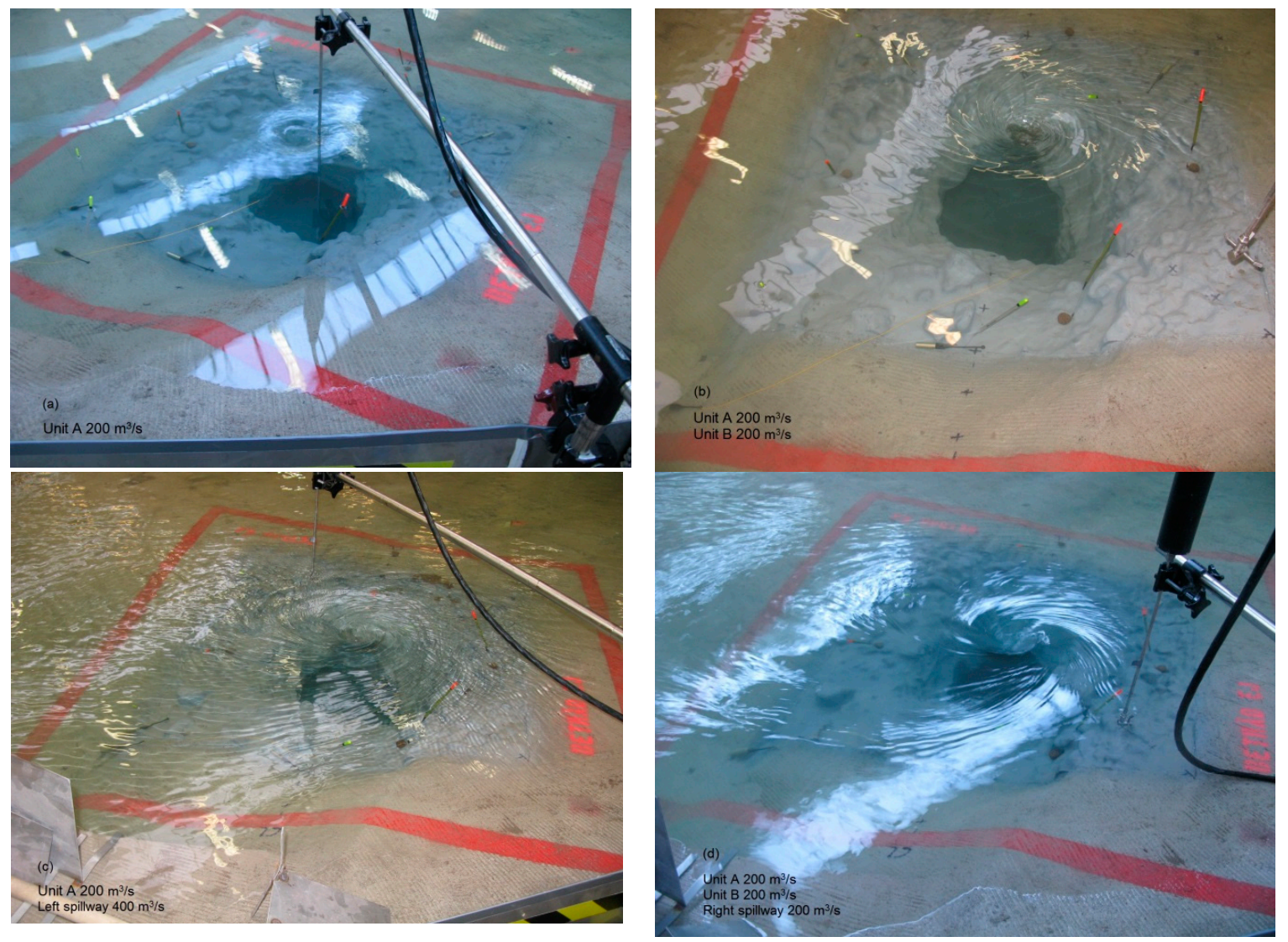

Figure 10. Vortex formations at the blasted intake of unit A. (a) only unit A in operation, $200 \mathrm{~m}^{3} / \mathrm{s}$; (b) both units in operation, $200+200 \mathrm{~m}^{3} / \mathrm{s}$; (c) unit A in operation, $200 \mathrm{~m}^{3} / \mathrm{s}$, combined with the left spillway, $400 \mathrm{~m}^{3} / \mathrm{s}$; and (d) both units in operation, $200+200 \mathrm{~m}^{3} / \mathrm{s}$, together with $200 \mathrm{~m}^{3} / \mathrm{s}$ in the right spillway.

Governed by the reservoir topographical geometry, it was understood that it was not possible to completely remove the swirling flow at the intake. Any measures to be undertaken would be a trade-off. The following principles were applied when a solution was sought: 
1. Normal reservoir water levels maintained during its installation

2. No additional intake headloss

3. Possibility to reduce local headloss at the intake

4. Functioning with ice cover during winter seasons

5. Reasonably low construction costs

6. Aesthetical aspects

As design recommendation, Rutschmann et al. [17] summarized a number of engineering examples of anti-vortex devices. These included the use of vertical walls, horizontal beams, racks etc. to mitigate dead water zones and elongate flow paths. Adoptions of buoys and floating rafts were also discussed to prevent air entrainment. For vertical intakes, radial piers, vertical vanes, and cover plates were useful countermeasures. Wang et al. [18] modified, for given water depth, the intake configuration to weaken the air-core vortex in front of a tunnel intake. Carriveau et al. [19] and Sarkardeh et al. [20] examined experimentally the effects of intake head-wall slope and trash-rack installation on the vortex strength reduction. The use of anti-vortex plates to improve the critical submergence condition was also found in Reference [21] for a vertical intake. There are many other practical cases and laboratory model results that illustrate design corrections for vortex mitigation. Understanding their site-specific conditions contributes to improving an intake design when vortex formation occurs.

The anti-vortex design solutions were mostly developed in connection with man-made intake structures; studies for an intake blasted and pierced underwater were rare. Its irregular geometry made it difficult to directly place any vertical piers or vanes on it. One needed to seek alternative options. A few potential countermeasures were evaluated in the model for their suitability. These included a floating frame of varied configurations above the intake. Such a frame should penetrate a certain depth in the water to be effective, which would result in extra headlosses at the intake. Besides, its adaptability to winter conditions was poor as ice cover exists in the water surface. The possibility to modify the surrounding terrain was also examined [2,22], without leading to significant improvement.

With reference to other engineering solutions, experiments showed that the most effective solution was the use of a rigid curtain extending to the dam (Figure 11). Its location was optimised with respect to both effectiveness and ease of placement. Initially, a whole wall was used. However, measurements indicated large loads on it, which would require costly anchoring efforts to keep it in place. By trial and error, the wall was instead divided into four segments (denoted as W1 to W4 from the dam), with an opening left between two neighbouring sections to let pass a certain amount of water and reduce the loads acting upon them. Segment W4 was placed close to the edge of the intake. As the vortex strength (in form of tangential velocity) reduced away from the intake perimeter, the segment width increased towards the dam to obtain roughly the same load on each segment.

An additional segment (W5), with a "sail" (W6) on its upper end, was placed behind segment W4 to further reduce the swirling flow. The sail inhibited the swirls directly above the intake. The upper edge of all the wall segments had an elevation of $+257 \mathrm{~m}$, i.e., $1 \mathrm{~m}$ below the lowest legal reservoir level (SG). Repeated tests showed that, with the solution, the vortex above the intake disappeared irrespective of flow combinations. A few minor vortices occurred, disappeared and recurred at intervals, which was acceptable. Measurements indicated that, thanks to the mitigation in the swirling flow, the local headloss at the intake was also reduced [23]. 


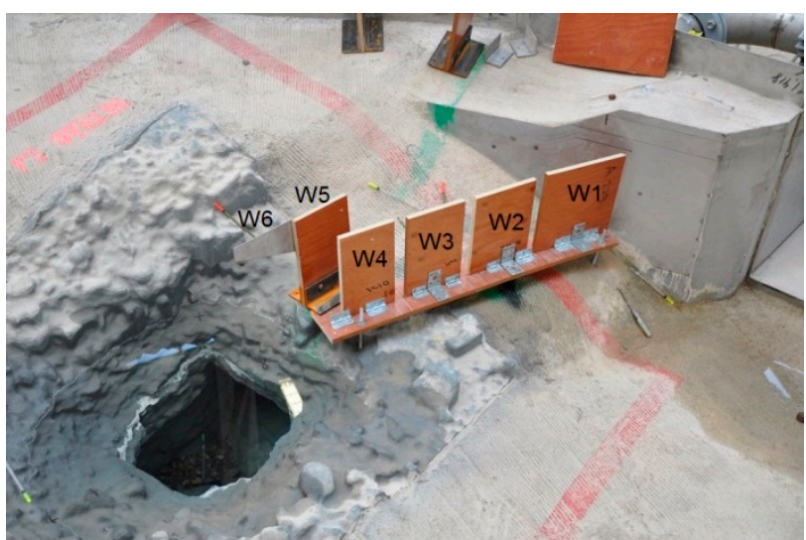

(a)

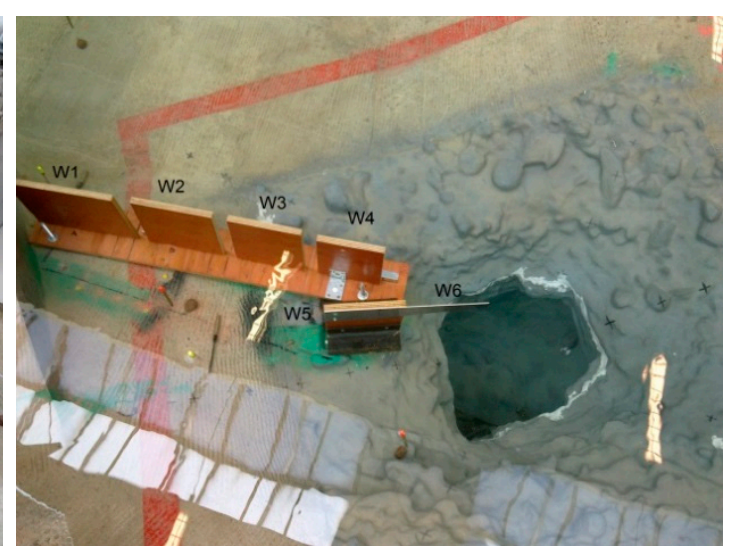

(b)

Figure 11. Vortex mitigation, the use of a segmented wall extending to the dam, consisting of segments W1-W6. (a) looking towards the dam; (b) looking from above

The experiments showed that the operation of unit A or both units led to anti-clockwise loads on the segments. The amount of energy remaining in the swirling flow direction accounted for the outcome. However, the load magnitude was limited. The stability of the segments was governed by the load at the spillway discharges. If the spillway gates were both open, the flow velocity to the right of the intake of unit A and the segmented wall, which were near to the spillway and the intake to unit $\mathrm{B}$, was high, thus giving rise to a water-level difference across the wall that produced the loading dominating the stability design.

A few combinations of segment widths were tested to determine the loading acting on them. The loading measurements were shown in Figure 12. With precision scales, loads were measured horizontally at a higher position above the segments (above the water surface); they were converted to the loads on the segment crests $(+257 \mathrm{~m})$.

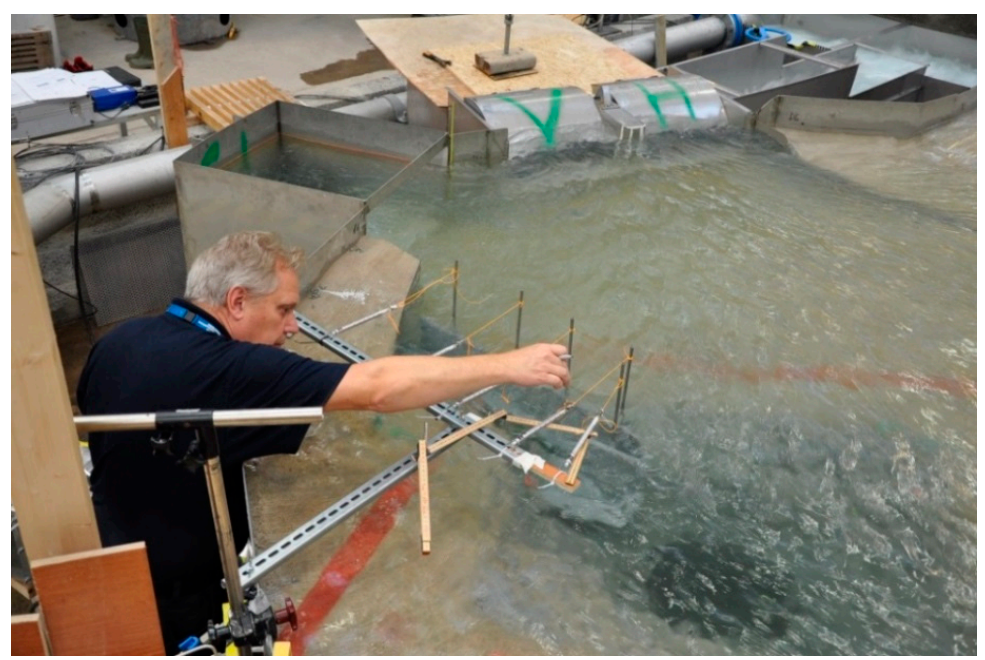

Figure 12. Measurements of loads acting on the segments.

To determine the design loading, the reservoir water level was set at $+296.4 \mathrm{~m}$ (DG $+0.9 \mathrm{~m}$ ) and the spillway flood discharge was $1900 \mathrm{~m}^{3} / \mathrm{s}$ (both gates at partial openings). Figure 13 illustrates the mean and maximum loads (per segment width) acting on the segment crests for such a width combination, 7.0, 5.0, 4.5, 4.0, 5.0, and $5.0 \mathrm{~m}$ from $\mathrm{W} 1$ to $\mathrm{W} 6$. The spaces between $\mathrm{W} 1$ and $\mathrm{W} 4$ were 0.8-1.0 m. For W1-W4, the mean loads varied between $0.8-1.4$ ton $/ \mathrm{m}$ and the maximum loads 
between $0.9-1.8$ ton/m. For W5 and W6, their loads fluctuated between $0.8-0.9$ and $0.25-0.28$ ton $/ \mathrm{m}$, respectively; the ranges of variation were however smaller than for W1-W4.

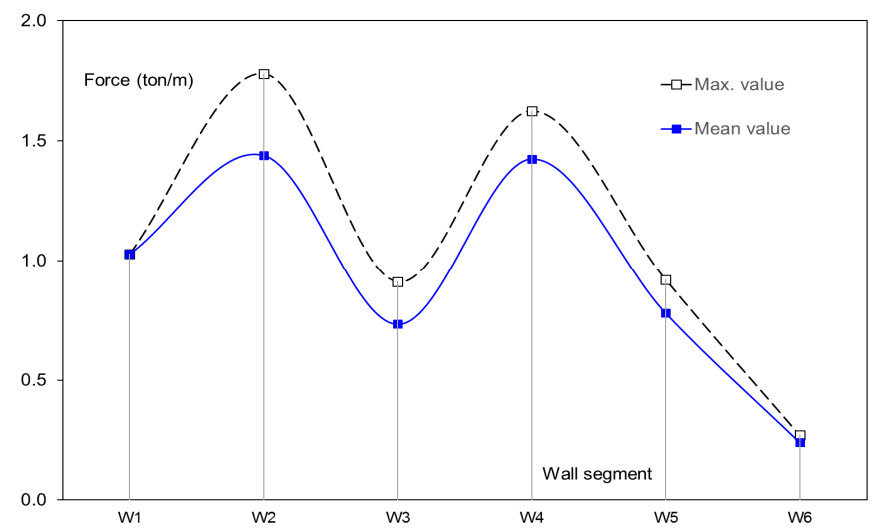

Figure 13. Loads (per meter) acting on the crests of the wall segments.

\section{Prototype Implementation}

On the basis of the model tests, a prototype solution was designed for implementation. Figures 14-16 show the arrangements of the countermeasure. In terms of segment width and spacing, the layout was adjusted in light of practical considerations. The fabricated steel structure was anchored into the reservoir bedrock. The anchored depth amounted to 3.7-5.2 m. It stretched from the reservoir bottom to $+257.0 \mathrm{~m}$, i.e., $1.0 \mathrm{~m}$ below the lowest legal level (SG). By doing so, the segments were kept submerged in the water and ice free during winter.

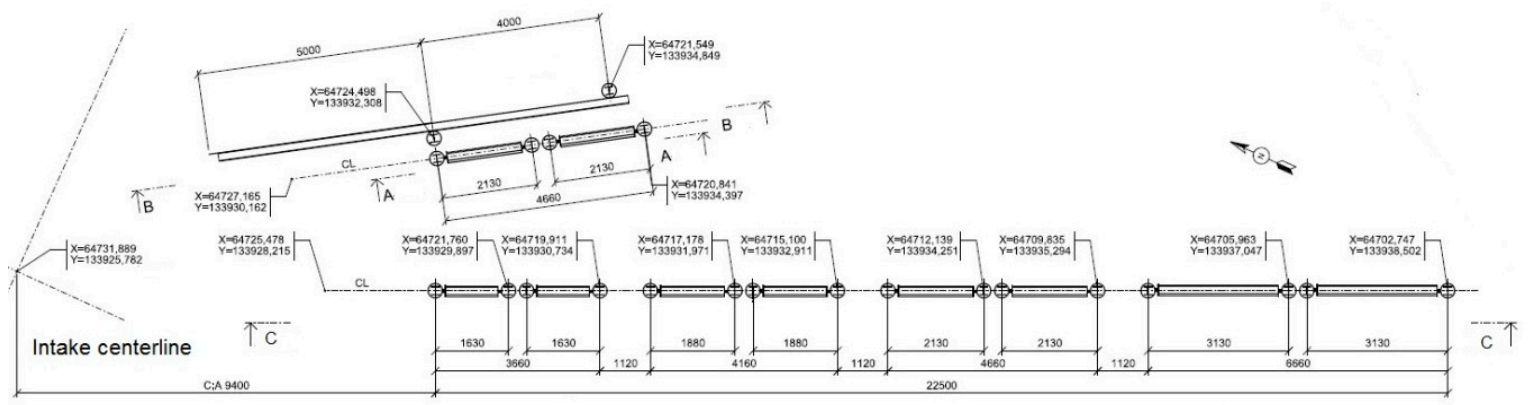

Figure 14. Layout of vortex countermeasure of mitigation.

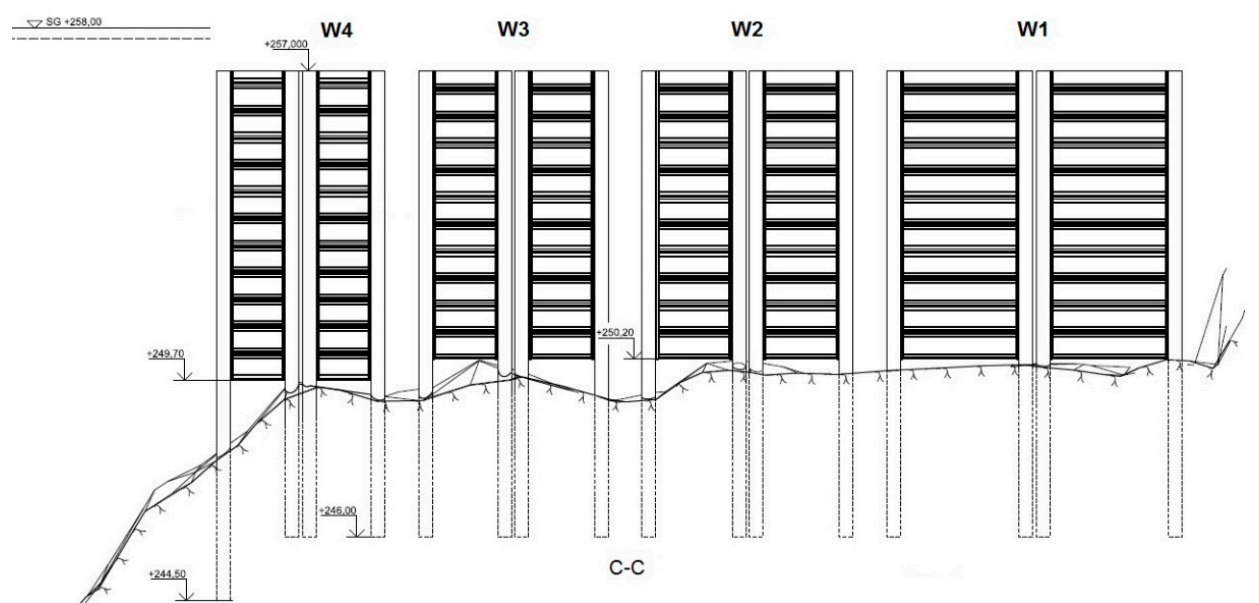

Figure 15. Cross-section of the wall segments (W1-W4). 

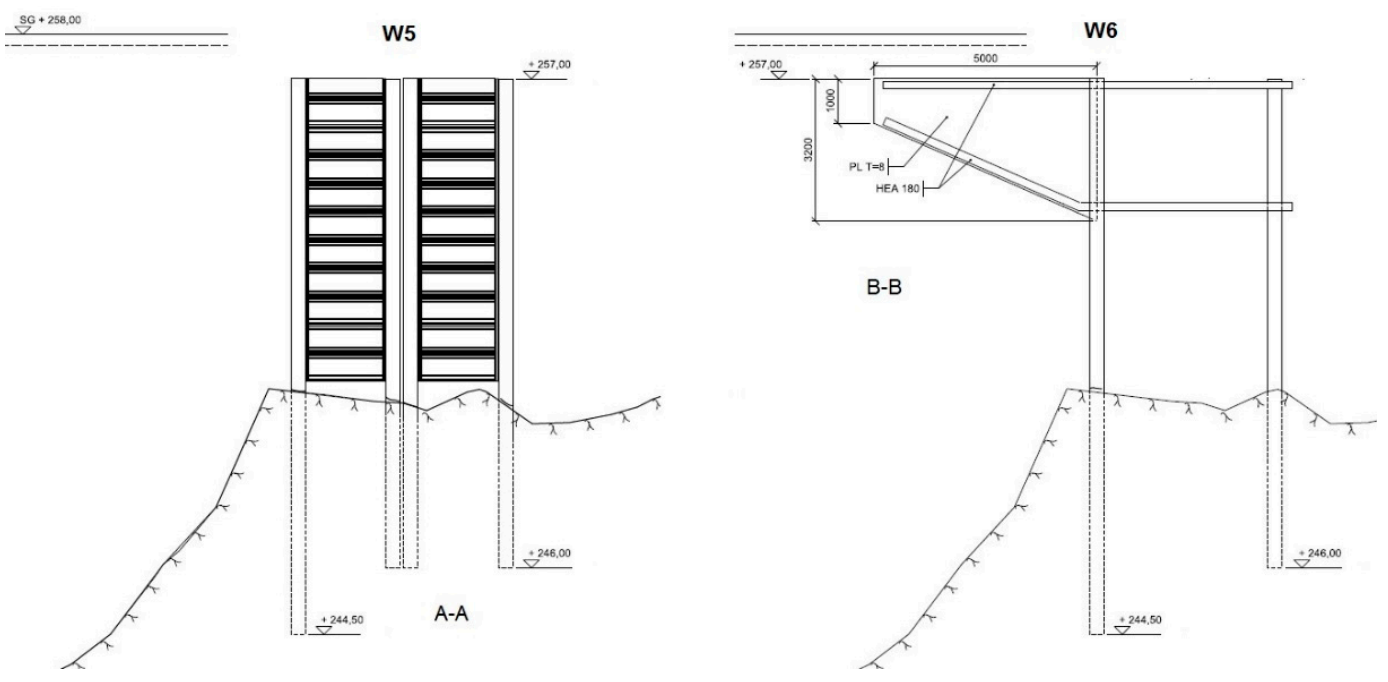

Figure 16. Cross-section of the additional wall segment (W5) with a "sail" (W6).

The four segments in a row were $22.5 \mathrm{~m}$ long. From the intake to the dam, their lengths increased, i.e., $3.66 \mathrm{~m}, 4.16 \mathrm{~m}, 4.66 \mathrm{~m}$, and $6.66 \mathrm{~m}$. The space between two neighboring segments was $1.12 \mathrm{~m}$, allowing a certain amount of water to pass through the wall. In such a way, the loading the wall needed to withstand was lower. The additional segment was $4.6 \mathrm{~m}$ long and was also placed close to the intake perimeter. The "sail", pointing towards the intake center, was installed on a separate frame and was $5 \mathrm{~m}$ long.

After the implementation, the vortex disappeared; only some minor vortices existed at the intake location, which agreed with the observations from the model tests. Unit A could be run at its full effect; no machine vibrations were observed. Minor stone and debris transport was reported in the headrace and it was expected to cease with time. The alongshore current at the embankment dam, caused by the vortex, no longer existed. The unit operated normally even with ice cover during winter seasons.

\section{Conclusions}

In the upgrade of Akkats power plant, a new waterway through the turbine unit was constructed. Its intake was formed through lake tapping, a complex dynamic phenomenon involving a mixture of blasted rock masses, water, air, and gas. Laboratory tests were performed to evaluate, in an approximative manner, the impact of the underwater blasting. To reduce the upsurge in the gate shaft and the force on the wall sealing the penstock, the rock plug was removed with sequential blasting.

Because of insufficient water depth, anti-clockwise swirling flows occurred at the intake during the commissioning, giving rise to undesirable consequences for the plant operation. As part of the design process, physical model tests were performed. A countermeasure, in form of a segmented wall extending from the intake edge to the dam, was found to effectively suppress the swirling flow. With its implementation in the prototype, the intake vortex disappeared; only a few minor intermittent vortices remained. The wall contributed also to a reduction in the headloss at the intake.

The hydraulic model for the vortex mitigation was based upon the Froude law of similarity. At the intake, the viscous and surface tension forces (represented by the intake Reynolds and Weber number) were, as known, less important than the gravity (represented by the intake Froude number). Despite the large model size, the Reynolds and Weber numbers were still not high enough; they did play a role, though limited, in the vortex behaviors, especially when unit A operated at partial loads [13,24]. The study focused, however, on the qualitative rather than quantitative aspects of the swirling flow and the countermeasure for its mitigation. 
The experimental procedures and the segmented wall proposed as a vortex mitigation solution have reference value for similar flow situations with vortex formation, especially when the reservoir water is shallow.

Author Contributions: J.Y. was responsible for the lake tapping tests. C.-M.H. was project leader for the vortex mitigation model tests, with participations from J.Y. and P.A. The paper was written by J.Y., with the help from P.T. for post-processing the test results.

Funding: This research was funded by Vattenfall Vattenkraft AB.

Acknowledgments: Participants in the study included also Mats Billstein, Anna Helgesson and Ulf Aurosell. Mikael Östlund helped with the intake terrain data and graphics. The authors would like to thank the five anonymous reviewers for their comments and suggestions that have contributed to improvement in our manuscript.

Conflicts of Interest: The authors declare no conflict of interest.

\section{References}

1. Wikström, L. Akkats Hydropower Station, Refurbishment Technical Description; Project Report No. 07:4; Vattenfall Power Consultant: Stockholm, Sweden, 2007.

2. Yang, J.; Billstein, M.; Engström, F.; Strand, R. Experimental studies on intake headloss of a blasted lake tap. IOP Conf. Ser. Earth Environ. Sci. 2014, 22, 042011. [CrossRef]

3. Solvik, Ø. Underwater piercing of a tunnel. Water Power Dam Constr. 1984, 11, 33-36.

4. Stormo, Ø.H. Tunnel breakthrough beneath $85 \mathrm{~m}$ water at Ringedalsvatn. In Tunnelling Technology, 2nd ed.; Norwegian Tunnelling Society: Oslo, Norway, 1987.

5. Sharma, H.R. Underwater tunnel piercing. In Proceedings of the International Symposium on Tunneling for Water Resources and Power Projects, New Delhi, India, 19-23 January 1988.

6. Nuddar, S.N. Geotechnical aspects of the design of underwater lake tap in Koyna hydroelectric project (stage IV). In Proceedings of the Workshop on Applications of Rock Mechanics, Tools and Techniques, Nagpur, India, 15-17 January 2010.

7. Sandvik, J.A. Model testing of underwater piercing of a tunnel. In Hydropower Tunnelling, 3rd ed.; Norwegian Tunnelling Society: Oslo, Norway, 1984.

8. Berdal, B.; Buen, B.; Johansen, J. Lake tap-The Norwegian method. In Hydropower Tunnelling, 3rd ed.; Norwegian Tunnelling Society: Oslo, Norway, 1984.

9. NTNU-Anleggsdrift. Underwater Tunnel Piercing; Project Report No. 19-99; Norwegian University of Science and Technology: Trondheim, Norway, 1999.

10. Yang, J. Model Tests of Underwater Tunnel Piercing in Refurbishment of Akkats Power Station; Project Report No. U10:8; Vattenfall R\&D: Älvkarleby, Sweden, 2010.

11. Yang, J. Underwater tunnel piercing in refurbishment of Akkats power station. In Proceedings of the ICOLD Annual Meeting and Symposium, Hanoi, Vietnam, 23-26 May 2010.

12. Odgaard, A.J. Free-surface air core vortex. J. Hydraul. Eng. 1986, 112, 610-620. [CrossRef]

13. Jain, A.K.; Garde, R.J.; Ranga Raju, K.G. Vortex formation at vertical pipe intakes. ASCE J. Hydraul. Div. 1978, 104, 1429-1445.

14. Knauss, J. (Ed.) Swirling Flow Problems at Intakes; Balkema: Rotterdam, The Netherlands, 1987.

15. Yildırım, N. Critical submergence for a rectangular intake. J. Eng. Mech. 2004, 130, 1195-1210. [CrossRef]

16. Yıldırım, N.; Kocabaş, F. Prediction of critical submergence for an intake pipe. J. Hydraul. Res. 2002, 40, 507-518. [CrossRef]

17. Rutschmann, P.; Volkart, P.; Vischer, D. Design recommendations. In Swirling Flow Problems at Intakes; Knauss, J., Ed.; Balkema: Rotterdam, The Netherlands, 1987; pp. 91-100.

18. Wang, Y.K.; Jiang, C.B.; Liang, D.F. Study on the critical submergence of surface vortices and the design of anti-vortex intakes. Sci. China Technol. Sci. 2011, 54, 799-804. [CrossRef]

19. Carriveau, R.; Kopp, G.A.; Baddour, R.E. Free-surface stretching-sustained intake vortices. J. Hydraul. Res. 2009, 47, 486-491. [CrossRef]

20. Sarkardeh, H.; Zarrati, A.R.; Roshan, R. Effect of intake head wall and trash rack on vortices. J. Hydraul. Res. 2010, 48, 108-112. [CrossRef] 
21. Borghei, S.M.; Kabiri-Samani, A.R. Effect of anti-vortex plates on critical submergence at a vertical intake. Sci. Iran. Trans. A Civ. Eng. 2010, 17, 89-95.

22. Yang, J.; Liu, T.; Bottacin-Busolin, A.; Lin, C. Effects of intake-entrance profiles on free-surface vortices. J. Hydraul. Res. 2014, 52, 523-531. [CrossRef]

23. Helgesson, A.; Billstein, M. Evaluations of Local Headlosses Due to Modified Intake Geometries of Akkats Unit G2; Research Report PM U13-42; Vattenfall R\&D: Älvkarleby, Sweden, 2013.

24. Chaudhry, H.; Reddy, H.P. Mathematical modeling of lake tap flows. J. Hydraul. Eng. 2011, 137, 611-614. [CrossRef]

(C) 2018 by the authors. Licensee MDPI, Basel, Switzerland. This article is an open access article distributed under the terms and conditions of the Creative Commons Attribution (CC BY) license (http://creativecommons.org/licenses/by/4.0/). 